\title{
Lancisi sign
}

\section{Sunil Kumar Srinivas, Prabhavathi Bhat, Navin Agrawal, Cholenahally Nanjappa Manjunath}

Department of Cardiology, Sri Jayadeva Institute of Cardiovascular Sciences and Research, Bangalore, Karnataka, India

\section{Correspondence to} Dr Navin Agrawal, drnavinagrawal@gmail.com

\section{DESCRIPTION}

A 60-year-old woman with rheumatic heart disease presented with New York Heart Association class III breathlessness, swelling of abdomen and lower limbs for 3 months. She had undergone open mitral commissurotomy 18 years back for severe mitral stenosis. On examination, she had elevated jugular venous pulse with prominent systolic ' $v$ ' waves known as 'Lancisi sign' (figure 1A,B; videos 1 and 2). Cardiac auscultation revealed a loud first heart sound, a loud pulmonary component of the second heart sound, an apical mid-diastolic rumble and a holosystolic murmur at the left lower sternal border that increased with inspiration. Peripheral pitting oedema, ascites and enlarged pulsatile liver were also noted. ECG showed atrial fibrillation with controlled ventricular rate and right ventricular (RV) hypertrophy. Chest X-ray posteroanterior view revealed cardiomegaly with CT ratio of $0.80, \mathrm{RV}$ apex, dilated right atrium (RA) and pulmonary artery (figure 1C). Two-dimensional echocardiography confirmed the presence of severe mitral stenosis, dilated left atrium, RA, RV and severe tricuspid

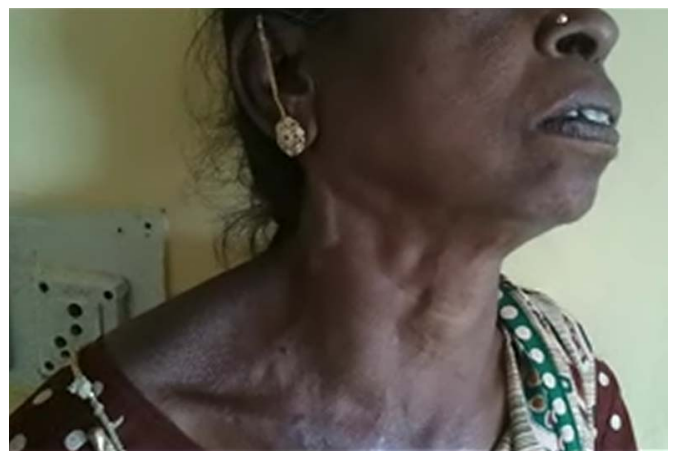

Video 1 Elevated jugular venous pulse with prominent systolic $v$ waves seen in antero-lateral view.

regurgitation with non-coapting tricuspid valve leaflets (figure $1 \mathrm{D}$, video 3 ). She underwent successful mitral valve replacement with tricuspid annuloplasty and maze procedure. At 6 months follow-up she had significant clinical improvement with mild tricuspid regurgitation.
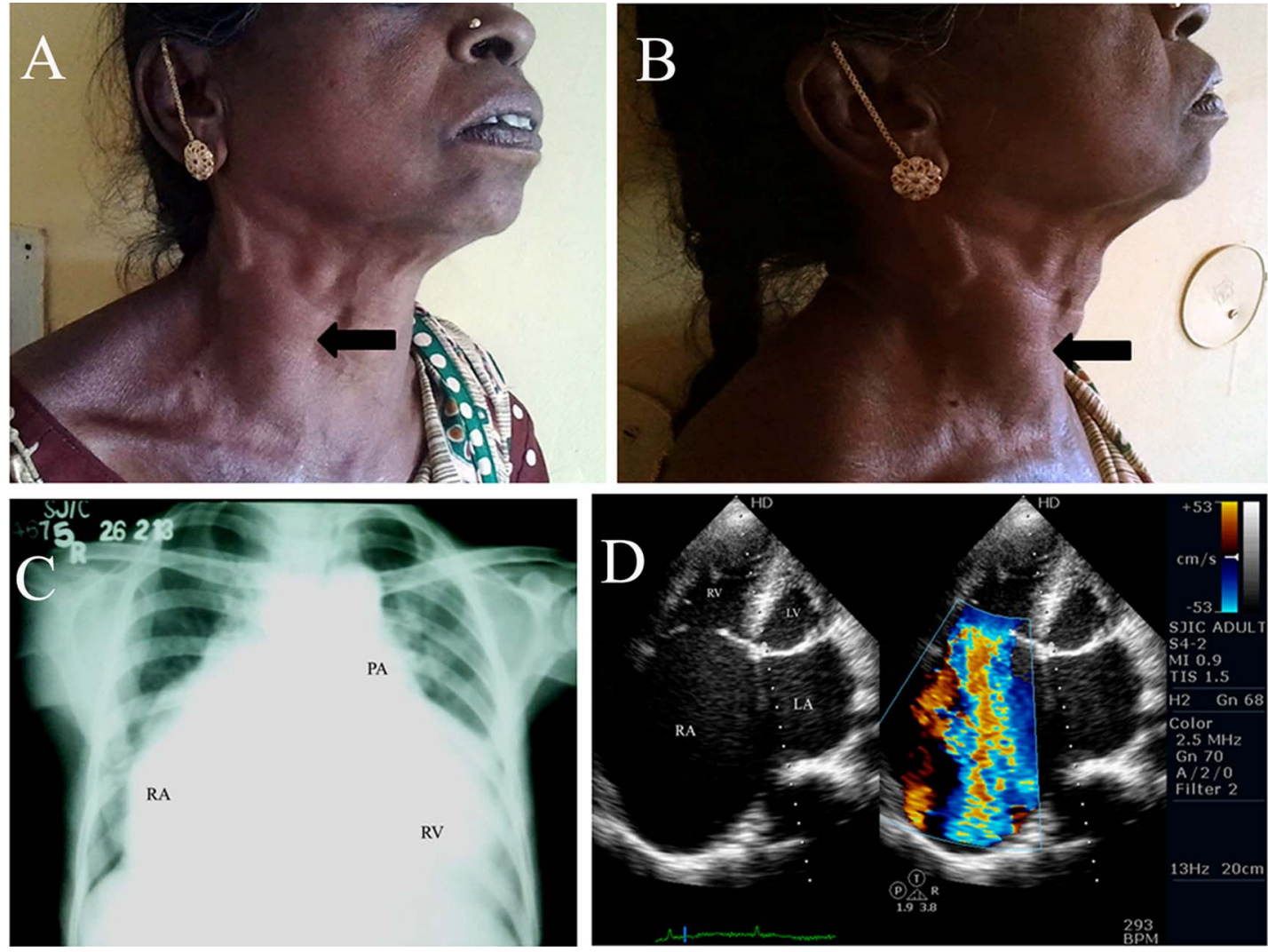

Figure 1 (A) Image showing elevated jugular venous pulse (JVP) in the anterolateral view. (B) Image showing elevated JVP in the lateral view. (C) Chest X-ray posteroanterior view showing cardiomegaly, right ventricular (RV) apex, dilated right atrium (RA) and pulmonary artery (PA). (D) Transthoracic echocardiography showing non-coapting tricuspid leaflets with severe tricuspid regurgitation (TR).

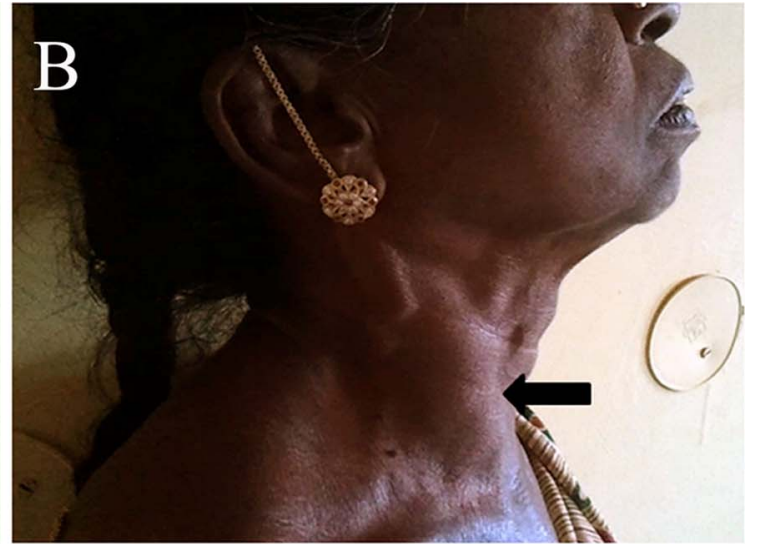

To cite: Srinivas $S K$, Bhat $P$, Rep Published online:

[please include Day Month Year] doi:10.1136/bcr-2013200023 


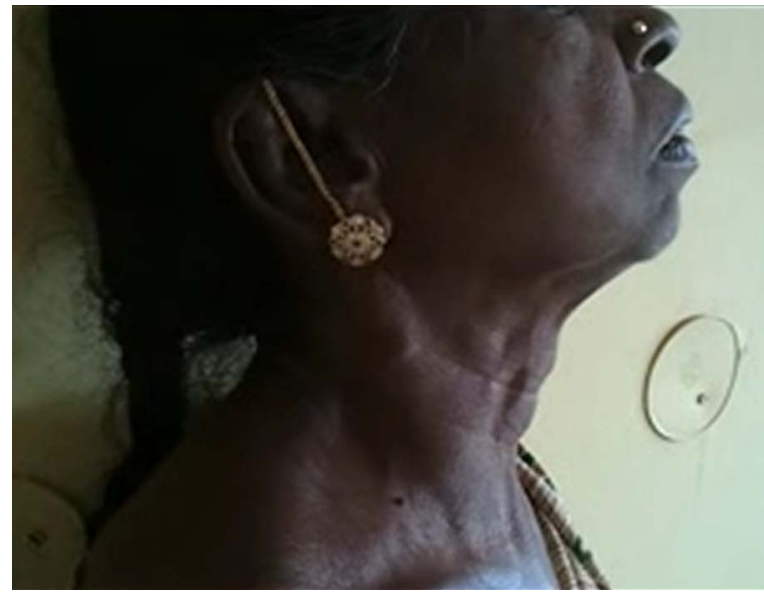

Video 2 Elevated jugular venous pulse with prominent systolic $v$ waves seen in lateral view.

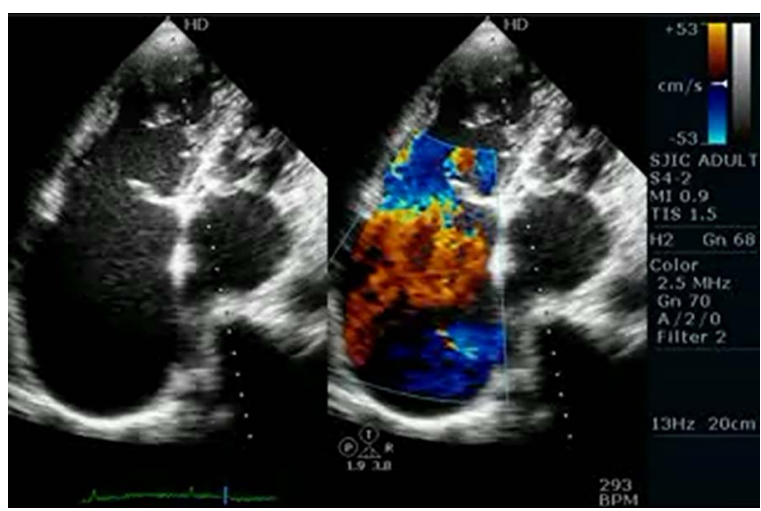

Video 3 Transthoracic echocardiography showing non-coapting tricuspid leaflets with severe tricuspid regurgitation.

\section{Learning points}

- Lancisi sign is defined as 'a large systolic jugular venous wave caused by tricuspid regurgitation replacing the normal negative systolic trough (' $x$ ' descent) ${ }^{1}$.

- These waves are also known as $C-V$ waves, a manifestation of severe tricuspid regurgitation. ${ }^{2}$

- These patients require tricuspid annuloplasty in addition to corrective surgery for contributory disease.

Contributors SKS and NA evaluated the patient and prepared the manuscript. PB and CNM guided, edited and finally approved the manuscript.

Competing interests None.

Patient consent Obtained.

Provenance and peer review Not commissioned; externally peer reviewed.

\section{REFERENCES}

1 Wehrmacher WH. Stedman's medical dictionary. 23rd edn. Baltimore, MD: Lippincott, Williams and Wilkins, 1976:1286.

2 Senguttuvan NB, Karthikeyan $\mathrm{G}$. Jugular venous $\mathrm{C}-\mathrm{V}$ wave in severe tricuspid regurgitation. N Engl J Med 2012;366:e5.

Copyright 2013 BMJ Publishing Group. All rights reserved. For permission to reuse any of this content visit http://group.bmj.com/group/rights-licensing/permissions.

BMJ Case Report Fellows may re-use this article for personal use and teaching without any further permission.

Become a Fellow of BMJ Case Reports today and you can:

- Submit as many cases as you like

- Enjoy fast sympathetic peer review and rapid publication of accepted articles

- Access all the published articles

- Re-use any of the published material for personal use and teaching without further permission

For information on Institutional Fellowships contact consortiasales@bmjgroup.com

Visit casereports.bmj.com for more articles like this and to become a Fellow 